\title{
Faith in Technology: Televangelism and the Mediation of Immediate Experience
}

Shane Denson, American Studies, Leibniz Universität Hannover

Email: shane.denson@engsem.uni-hannover.de

\section{Abstract}

This paper seeks to illuminate the experiential structures implied in the viewing of televangelistic programming - with particular focus on programming of the charismatic faithhealing variety that culminates in the televangelist's appeal to viewers to "touch the screen" and consummate a communion that transcends the separation implied by the televisual medium. By way of a "techno-phenomenological" analysis of this marginal media scenario, faith-healing televangelism is shown to involve experiential paradoxes that are tied to processes of social marginalization as well. Thus, it is argued, faith-healing televangelism functions as a call to viewers to mount a head-on confrontation with the technological infrastructure of secular modernity and thereby to effect a specifically material negotiation of evangelical culture's precarious balancing act between an entrenchment in and a selfmarginalization from the secular mainstream.

\section{Introduction}

Televangelism is an inherently modern form of religious practice, one tied inextricably to the modern technological media that enable its production, distribution, and consumption. ${ }^{1}$ And yet televangelism is favored as a platform for the communication of conservative and fundamentalist religious messages that are in many ways at odds with secular modern culture and its media. Televangelism is therefore caught up in a paradoxical situation: it is dependent for its very existence upon the same technologies of mass communication that have been instrumental in structuring and maintaining a world that conservative televangelists see as fallen or inauthentic, and televangelistic programs are therefore forced to share a media space (the airwaves, cable networks, and now the space of the digital) with the major channels and representatives of secular culture. This tension between conservative evangelical theology and the mediating technology of television has far-reaching consequences, including the specific experiential demands that televangelism puts on its viewers, and we fail to appreciate the tension's true import so long as we reduce it to a competition between an anti-modern message and a modern channel of dissemination. For, as I hope to demonstrate by way of a phenomenological analysis, televangelism is not so much about messages per se. It is instead about cultivating an experience of something immediate, something unmediated by language - a direct communion that overcomes spatiotemporal distances and the separation inherent in televisual mediation. Paradigmatic for this experience, and centrally at stake in the faithhealing variety of televangelism, is the worshipful communion of the holy spirit with a 
believer's body and soul. The question, then, is this: how can an inherently immediate experience be communicated through electronic media?

Posing the question in this way requires that we go beyond the dichotomies of form/content or channel/message and focus instead on the embodied experience of viewing televangelism. Recognizing that televangelism utilizes a variety of forms and modes of address, I seek not to reify one monolithic type of televangelistic experience but to address a paradigm case in which the tension between mediation and immediatism reaches its apex: the case of the televangelist faith-healer's appeal to viewers to "touch the screen" and consummate a laying on of hands at a distance. ${ }^{2}$ This extreme case is paradigmatic, I claim, not in the sense that it is somehow typical or representative of televangelistic programming at large, but in the sense that it focuses the basic sociocultural tensions and paradoxes at the heart of televangelism and transforms them into a robustly embodied, experiential paradox. The ultimate function of televangelism is not to disseminate a pre-existing (and pre-modern) message but to actively produce new constellations of discursive content and experience that are intrinsically tied to modernity and its technologies. Seen from this angle, the faith-healing televangelist's invitation to touch the TV screen is an invitation to confront modernity head on, to undergo not just a test of faith but to submit oneself to a technological ordeal in which a qualitatively new form of faith may emerge that is tuned to and inseparable from the technological conditions of modernity. It is this dynamic, generative potential of the experiential paradox that I seek to uncover in the following pages.

\section{Contextualizing Televangelism: The Modernity of Conservative Evangelicalism}

Televangelism must be seen in the context of the rise, over the past several decades, of conservative evangelical and fundamentalist denominations in the United States, which challenged reigning sociological theories about an ongoing secularization process. ${ }^{3}$ But if evangelicalism ${ }^{4}$ is in a significant sense at odds with secular society, it is important to realize that the communal life offered by conservative evangelical movements is deeply entrenched in the material, medial, and social contexts of secular modernity. Indeed, it is this entrenchment, I suggest, that shapes both the functions and the characteristic experiences of televangelism in particular. It thus behooves us to consider briefly the context of televangelism before we turn to a more detailed phenomenological analysis.

Conservative evangelicalism is hardly outside of mainstream culture. On the contrary, evangelical communities are structured through and through by modern organizational forms, and they resemble the structures of secular society to a remarkable degree. With regard to material and medial infrastructure, three phenomena deserve particular mention: 1) mass media (radio, television, and increasingly the Internet) are utilized to spread the gospel; 2) megachurches employ many of the same dramatic techniques as developed by televangelists, they use modern technologies such as video displays and sound systems to make the preacher's words and gestures accessible to members in the back rows, and, moving away (both spatially and structurally) from the neighborhood congregation and its close-knit familiarity, these churches reflect changes in (sub)urban life and an increased (need for) mobility; finally, 3) conservative religious pressure groups, utilizing both grass-roots organizational forms and sophisticated mass-media campaigns for the mobilization of their constituencies, exercise significant influence in the ostensibly secular realm of American politics. On their own, each of these three aspects is susceptible to an interpretation that 
distinguishes evangelical messages from the modern media through which they are communicated, as mentioned above. Taken together, though, and as they are integrated into a comprehensive evangelical subculture or (entrenched) alternative public sphere, they simultaneously efface that distinction and blur the lines between mainstream secular and conservative religious spheres. ${ }^{5}$

The evangelical public sphere, that is, is not situated outside of but very much within the modern world; it is articulated through large religious media networks (including print media, cable television channels, and websites), alternative entertainments and leisure-time activities (which adopt and adapt mainstream forms ranging from museums, magic shows, and dances to heavy metal concerts and dating services), and organized business networks (Christian yellow pages, Christian chambers of commerce). Generally, these "alternatives" are open to the public at large - on the same cable television systems, in public arenas open to believers and non-believers alike, and in the official yellow pages; what distinguishes them to those in the know is, ostensibly, a basis of faith shared by business owners and customers, culture producers and consumers. Thus, believers themselves might be able to appeal to a content/form distinction to articulate the difference between a mainstream culture and Christian alternatives that borrow generic formal structures and media packages from the former but - as in the case of Christian rock music - substitute a religious message for a secular one. However, it is important to realize that the organizations and practices in and through which the larger alternative public sphere is defined resist such treatment to the extent that they serve many of the same non-religious functions as their worldly counterparts.

The point is not that believers are insincere about their motivations or that communal faith is merely a pretense upon which they justify (to each other if not themselves) their extrareligious activities. Clearly, though, an evangelical-run car dealership seeks profits just like any other dealership; if fellow believers choose to purchase their autos there, it is not because those cars formally express or embody a Christian message. Automobiles, money, and the patronage of ostensibly Christian businesses have little if anything to do with religious content, and they can hardly be construed as media that would strengthen the faith of believers or convert their fallen brethren. Superficially, the situation is very different in the case of Christian music and televangelistic programming. But these phenomena as well are part of an overarching evangelical public sphere whose differences from mainstream culture are not as clearly articulated as they are loudly proclaimed. The overlap between the spheres - clearest in the realm of commerce - is perhaps one of the reasons why - particularly in the realm of Christian mass media - evangelical culture must demonstrate its difference again and again. Structurally, conservative evangelicalism's processes of group constitution are hardly distinguishable from those of any other modern group. Believers' performance of an opposition to secular modernity, I suggest, is necessitated by their factual and inescapable imbrication in it. The separation of form and content is not merely an academic invention; more fundamentally, it is a strategy by which practitioners of conservative religion are able to participate in and simultaneously distance themselves from the modern world. Viewed as a holistic religious practice in its own right, the drawing of the form/content distinction involves a precarious balancing act - but not a contradiction. Christian heavy metal is no more a parody of allegedly Satanist heavy metal than televangelism is an ironic commentary on mainstream television programming. These phenomena must be treated as serious religious practices, but not reduced primarily to expressions of faith. They are forms of modernity, but forms that allow their practitioners (whether producers or consumers) to "stay tuned" to this-worldly contexts while instilling a self-conscious perception of difference, a dissonance with mainstream society owing to an other-worldly instance. 
This, then, is the paradox of conservative evangelicalism as a product of modernity: that a distinction must be proclaimed and experienced where both form and function exhibit more similarity than difference from the surrounding culture. As a comprehensive context of mediation, an evangelical lifestyle reflects, expresses, and transforms contents that are both religious and secular in nature and origin; in this context, the concrete forms of religious practice simply cannot be neutral with regard to their contents, which are sometimes in harmony and sometimes in conflict. Again, this implies for the believer the performance of a balancing act between secular and religious identifications, and the evangelical public sphere must therefore provide a variety of openings that allow individuals to gauge and navigate the differences and overlaps, a variety of practices that differ according to how pronounced the experience of sameness or difference may be. It is through such practices that the alternative public sphere is collectively constructed, negotiated, and transformed. Like clothing suited to different occasions, or music that fits a particular mood, the practices that constitute an alternative public sphere offer not a homogeneous lifestyle but allow for inflections based on personal and temporary needs and preferences. Among these must exist both moderate experiences of relative conformity with secular society and, so that the perception of difference does not collapse, more extreme cases of dissonance. Televangelism, as one area in which the negotiations of evangelical identifications are performed, offers such a range of opportunities. Religious talk shows can serve moderate functions, televised church services may appear traditional, while charismatic faith healers cater to people in extreme situations. As extreme cases, these faith-healing programs are representative neither of televangelism or religious programming in general nor of the evangelical public sphere's larger strategies of negotiation with the modern world. Yet these atypical cases serve an important function in the context of such negotiations. They drive the paradoxical situation of modern evangelical believers to an extreme, force a confrontation with the paradox, and provide a test of faith an ordeal necessitated by the slippage between secular and religious realms and an opportunity to prove - and produce - more durable differences.

\section{Techno-Phenomenology and Televangelistic Faith-Healing}

To approach the experiential dynamics, tensions, and paradoxes involved in the extreme case, I propose a "techno-phenomenological" analysis that highlights the embodied experience of mediation. Fully aware that televangelical faith-healing is open to a variety of receptional modes (including cynical or critical modes enacted by viewers who situate themselves either inside or outside the alternative public sphere of conservative evangelicalism), my approach takes its cue from broadcasts' own manners of address. The analysis offered here therefore describes an ideal situation, in the sense that it takes faith-healing televangelism's internally established viewing norms at face value and assumes a viewer who does the same. In other words, I bracket out patterns of actual reception that deviate from this normative ideal and instead ground my investigation in the shows' self-presentational modes - i.e., in faithhealing televangelism's performance of implicit self-definitions that it asks viewers to take seriously. Televangelists themselves are surely aware that this request is not always heeded, but the long broadcast history and financial success of a Benny Hinn, ${ }^{7}$ as one example among many, must be counted as evidence that many viewers do indeed take TV faith healing seriously - as circumstantial evidence, that is, that the ideal situation is not purely hypothetical or fictitious. The question, then, is this: what relations are implied and enacted in an ideally "straight" viewership between socially situated, concretely embodied subjects and the objects and apparatus of televisual mediation? 
Before I can begin to offer answers, however, it must be emphasized that the methodological ideality at the heart of this investigation has nothing to do with the idealism with which phenomenology, rightly or wrongly, is often charged. The technophenomenology practiced here emphasizes the material nature and situatedness of phenomena and takes its lead from (Merleau-Pontyan) existential rather than (Husserlian) transcendental phenomenology; whereas Husserl's form of phenomenological practice is seen by many to have issued in idealism and essentialism, Merleau-Ponty emphasized the body and the diffuse materiality of the world as the basis for all subjective and conceptual phenomena. Furthermore, I follow philosopher of technology Don Ihde in insisting that materially instantiated mediating technologies are never neutral with regard to human thought, action, or experience; rather, they transform the intentional subjectivities that engage them, thereby militating against the notion of a stable transcendental ego. ${ }^{8}$ As a correlate, media cannot be reduced phenomenally to transparent "channels" of communication wherein pre-existing "messages" or "contents" are transported unchanged and without regard for the "form" of their mediation. ${ }^{9}$ In the case of televangelistic faith healing, as we shall see, failure to recognize this fact contributes, in part, to the widespread dismissal of viewing subjects as hopelessly naïve: as somehow ignorant of the fact that they cannot simply reach out and touch the faith healer through the TV screen. Naïve or not, I propose that the viewer who takes seriously and acts upon the appeal to "touch the screen" engages with the medium in a much more complex manner that itself phenomenally highlights the non-neutrality of technological mediation. Accordingly, the question posed above concerns the manner in which embodied viewers, under admittedly ideal conditions, relate materially to the nonneutral medial phenomena of televangelistic faith healing.

The assumption of ideal conditions (viz. "serious" viewership according to internally articulated normative ideals) should not be misunderstood as according a central, paradigmatic, or otherwise privileged position to the extreme case of televangelistic faith healing. ${ }^{10}$ Such a treatment would not only be sociologically unrealistic (for touching the screen remains "freakish" not only in the eyes of secular society but also within the alternative public sphere of conservative evangelicalism); moreover, ignoring this social freakishness would render the description phenomenologically incomplete as well. "Serious" viewers of faith-healing programs are situated - variously, of course - in the alternative public sphere of modern evangelicalism, but it is precisely from within this sphere that some of the most vehement criticisms of televangelist faith healers derive. Secular disbelievers may snicker at what they take to be simple charlatanry, but they are not likely to raise charges of religious heresy. Evangelical believers, however, have a larger stake in the phenomenon and really stand to lose something if their faith is identified with televangelists' all-too-visible scandals of exploitation, hypocrisy, and possible blasphemy - hence the importance of evangelical-run watchdog groups. Since subjectivity is always socially situated, divisions within the evangelical subculture cannot be ignored in a phenomenology of viewers' experiential relations to technologically mediated religion. To understand televangelistic faith healing as an embodied experience, it must be evaluated in terms of its uneasy connection with, and disparity from, other facets and sub-formations of the larger evangelical public sphere. Centrally, it must be measured against the dominant style of congregational, face-toface worship against which televangelism in any mode is most obviously distinguished and, for the most part, marginalized.

Indeed, this marginality demands further attention in order to grasp the ideal dynamics of televangelistic faith healing. Specifically, the internal norms of faith-healing televangelism 
must be set against two external sets of standards: those of "normal" television viewing practices and those of evangelicalism's normative model of in-church worship. Together, these two sets - each of which demands phenomenological analysis of its own - help to explain why outside observers may find it hard to take televangelistic faith healing seriously, and - crucially - they articulate internal obstacles for straight-faced viewers who seriously strive for the experiential fulfillment of its ideal receptional situation. That is, "normal" TVviewer relations on the one hand and "normal" worship practices on the other show us why the experience falls short of the ideal not only for (both secular and religious) critics but also often for devoted viewers themselves. The idea that people could earnestly endeavor to touch one another through the TV screen seems ludicrous to the average television viewer, and from a mainstream religious point of view it must appear, if not heretical, then at least doomed to failure. Paradoxically, though, what from an external perspective marks an essential shortcoming of televangelistic media - the physical isolation and disconnection of viewers by mass-media channels - is itself taken up in the extreme/marginal experience of televisual faith healing and reappropriated as an internal element of that experience. The challenge of overcoming this isolation, which stems from the modern secular world, becomes a central test of the viewer's faith; if he or she fails to make contact, this can be ascribed to a shortcoming not of the medium but of the viewer, whose faith has proved inadequate. Paradoxically, then, in this "failure" we find a reason both for critics to reject televised religion and for devoted viewers to keep coming back for more, to submit themselves repeatedly to the ordeal, in the hopes that they will eventually develop the strength to overcome all obstacles and receive the blessings of grace.

Thus, though my investigation aims at an ideal description and explication of "serious" engagements with faith-healing televangelism, which necessitates a phenomenological bracketing of non-serious, critical, or otherwise "deviant" viewing modes, my analysis must remain sensitive to the social bracketing of devoted viewers whereby both secular society and the mainstream of the evangelical public sphere distance themselves from an "abnormal" phenomenon and mark it as socially deviant. Only against the background of a phenomenological description of mainstream worship and television-viewing practices can the social and phenomenological stakes of a technologically structured test of faith be made apparent.

\section{Outside Perspectives: Going to Church and Watching TV}

In an article entitled "A Phenomenological Study of In-Church and Televised Worship," Richard F. Wolff (1999) analyzes the dynamic corporeal-sensual experiences of traditional and televisual worship practices on the basis of first-hand descriptions obtained in interviews with churchgoers. Though limited in scope by the choice of his test group - "members of a small, predominantly white Lutheran congregation in Athens, Ohio" (p. 221) ${ }^{11}$ - Wolff's findings are invaluable in coming to terms with the external and internal obstacles to the ideal receptional experience of televangelistic faith healing, and his analysis can stand as a model of normative worship experience for mainstream (American) Protestantism generally and for conservative evangelicalism in particular. ${ }^{12}$

Briefly, Wolff collects interviewees' descriptions of: 1) an essential contrast between ecclesiastical and "everyday" experiences, 2) the sensory experience of a typical church service, and 3) the intersubjective relations implied among human and divine agents. On the basis of these descriptions, Wolff conducts a phenomenological reduction that reveals the 
"emergent themes" of hierarchy, immersion, and freedom - themes that Wolff identifies as "the essential constituent elements of ecclesiastic experience" (p. 221). Finally, he compares the structures of this experience to respondents' descriptions of televised worship, which they find "less satisfying" than church (p. 232).

Church is distinguished from everyday life in a number of ways. It marks, for Wolff's respondents, a respite from the demands of work and time out from the conflicts and chaos of a secular world. Church both ends the week and begins a new one, offering "a temporal point of reference, a present experience from which worshippers reflect on the past and find renewal for the future" (p. 222). (Though Wolff is not concerned with conservative evangelicalism, we can easily see how important this separation of church from daily, secular life is in negotiating an evangelical public sphere's connections and differences vis-à-vis modernity, even - and perhaps especially - if the separation is challenged in practice by that public sphere's expansions beyond the church walls.) Moreover, during the church service worshippers experience, in the words of one respondent, "a suspension of time," an atemporal present-ness which Wolff generalizes as "a defocusing on the passage of time" in ecclesiastic experience (p. 223).

Within this setting, auditory, visual, and tactile senses are subject to "heightened focus" (p. 223) and transformation. Silence promotes a meditative focus and self-examination, forming the ground upon which worshippers create an immersive "group identity," for example through the "auditory unity" of collective singing (p. 223). With regard to sermons, prayers, and readings, "listening is the principal mode of engagement" (p. 224), and both "aberrant sounds" (p. 223) and distracting sights threaten to disrupt worshippers' intentional directedness. Generally, a "disengagement of the visual" (p. 224) is experienced as necessary for immersion in the congregational collectivity, which transcends the visually perceivable bodily boundaries of its individual members; more radically still, vision must be bracketed in order to establish a connection with God, who categorically transcends spatial locatability and visibility altogether. Centrally, making contact with God is dependent on a heightened sense of "tactility and bodily presence" (p. 224), where the palpable nearness of human others engaged in collective worship gives way to an experience of immersive indistinction between self and other, human and divine.

Thus, intersubjective relations are also subject to transformation. The pastor or preacher may be a friend (or even business partner) outside of church, but during the worship service he or she occupies a privileged position as a "site of interaction" between congregants and biblical, institutional, and divine others (pp. 225-26). A passive relation on the part of the churchgoer is therefore experienced as appropriate (p. 225). The congregant's own self is "willingly separated from itself," transformed in a transcendence of its everyday roles and relations to others, "stabilized" by its reconnection to a divine foundation, and thereby "renewed" for the trials of the outside world (p. 226). God, of course, is the central agent of this transformation. Both distinguishable as an other and likewise inclusive of all existence, God is experienced as "necessarily ambiguous," as an a-rational "unity" of presence and absence that is not concretely locatable but suffusedly present in the human collective engaged in worship (pp. 226-27).

As Wolff argues, this temporal, corporeal, and intersubjective experience of in-church worship is dependent upon a number of hierarchies: church over the secular world, the religious self over the everyday self, the collective "we" of the congregation over the isolated "I," the pastor as focal "site of interaction" over the passive congregants, and finally God 
over humanity (pp. 227-29). Hierarchy implies separation, but this separation serves in worship as a necessary "background against which immersion becomes foreground" (p. 229). The visual, which implies perceptions of distance, gives way to the auditory, which unifies congregants by surrounding them; the self is dissolved in an immersive community; and an "interwoven corporeality" emerges that connects all things to God (pp. 229-30). Finally, immersive interconnectedness is experienced as freedom from the limitations of the everyday self that is tied to a secular and self-interested world (pp. 230-31).

For Wolff's interviewees, watching televised worship services is inherently "less satisfying" than in-church worship (p. 232), a fact which Wolff accounts for by comparing the phenomenal structures of the two experiences. For one thing, "[w]hereas church is apart from the everyday, televisual experience is integrated into everyday life: physically, TV is located in the home; temporally, it is watched daily" (p. 232). Moreover, in church experience one concentrates on secular life in order to transform it, but television merely distracts the viewer from personal problems without transcending and transfiguring quotidian experience (p. 232). And because television is typically "not engaged exclusively, but combined with other activities" in the flow of daily life, watching TV is not regulated by the intentional directedness that is expected in church (p. 232). Furthermore, Wolff's respondents link these formal differences to the typical discursive contents of televisual as opposed to ecclesiastic narratives: TV is populated with secular gossip, scandal, and intrigue; "[w]hereas church provides security, television is perceived as dangerous" (p. 232).

As for specifically religious programming, Wolff's respondents describe a feeling of "embarrassment" when watching televised worship services that is linked to TV's confusion of private experiences and public media (pp. 232-33). Of course, in-church worship is a shared activity, not completely private, but closed off from the interrogating gazes of the outside world. When televised, it is opened to unsympathetic views, critical or distanced perspectives that fail to conform to the intentional focus of the congregation as a collective body. Just as the physical presence of a critical observer could induce an uncomfortable selfconsciousness and awareness of one's actions that distracts from participatory immersion, so too does the reflective awareness of a possible disparity lead to embarrassment in televisually viewing worship services without being engaged in them. A guilty sense arises that one is voyeuristically violating the sanctity of sacred boundaries - or, alternatively, that one is witness to a congregation's own indecent exhibitionism. ${ }^{13}$ As one respondent puts it, "you're on the outside looking in" (p. 233), supporting Wolff"s conclusion that "[t]he actual bodily presence participants experience in church is what is most missing in televised worship" ( $p$. 233). His respondents feel like mere "spectators," "cut off" from the interaction and "corporeal immersion" that is essential to ecclesiastic experience; for "television viewing," according to Wolff, "ideally involves a bracketing of the body" and promotes an immersion in "another world" that is not my corporeal-physical own (pp. 233-34).

\section{Internal Modifications: Faith and/in Technology}

Combining phenomenologies of ecclesiastic and televisual experience, Wolff's investigation articulates both of the major (external) obstacles to taking televangelistic faith healing seriously. Again, the dynamics of in-church experience revealed by Wolff, although tuned to the descriptions of a Lutheran congregation, hold true as an ideal of worship for the majority of conservative evangelical believers as well. Crucially, this experience is dependent upon the corporeal co-presence of worshippers in a shared physical space of fellowship. And 
television, both physically and phenomenologically, is seen as inherently incompatible with the requisite interaction and contact. Thus, it is hard to see how any but the most deluded of viewers could take seriously the televangelist faith healer's appeal to touch the screen. But if, as I have suggested, the ideal situation of "serious" viewership according to the genre's internal norms of reception is not naively ignorant of, but more subtly responsive to, external ideals of worship and television viewership, then the extreme case must address its viewers in such a way that demands essential modifications of the phenomenal structures and conventions of both sorts of experience. What, then, are the conditions upon which a viewer can earnestly engage with the faith healer by televisual means?

To approach this question, we should first note that the dissatisfaction with televangelism expressed by Wolff's test group stems directly from the combination of their ideal worship experience and a televisual broadcast format that directly mimics (i.e. reproduces without alteration) the structures and rituals of in-church worship. That is, the "televised worship services" to which they respond are nothing other than normal church services, merely mediated by the technical apparatus of video camera and television set. Thus, the camera's object is a church service that is formally identical to the services the respondents attend weekly, and it therefore retains the ideal norms of in-church worship as its own; but as a medial object, the church service is opened for a type of subjective reception (a view from outside) that is incommensurate with the active participation expected of the churchgoer (an experience from inside). There is a mismatch of norms as much as of forms; dissatisfaction, as a result, is inevitable. But the extreme case of televangelistic faith healing, which deviates radically from the pre-established norms, forms, and rituals of the traditional church service, simply cannot be judged by these standards. For, as we shall see, televangelistic faith healing does not operate in the manner of televised worship services at all; it does not situate its camera in the position of a congregant and aim thereby to reproduce the audio-visual impressions of a churchgoer, does not take as its object a form of worship that is independent of the camera, but instead produces a new form of worship that requires technical mediation as an essential element of its experience.

Before explicating these structures further, we should also note a basic tension in Wolff's phenomenology of televisual experience. On the one hand, TV is seamlessly integrated into daily life - viewing takes place simultaneously with "sewing, cooking, reading, eating" (p. 232 ) - so that there is "a lack of intentional focus on the television" (p. 232). On the other hand, viewers are said to be "immersed" in "another world," seemingly so engrossed by the spectacle that they forget their surroundings and their very bodies (p. 234). The disparity here, I contend, is indicative of the fact that no single phenomenological description can be adequate to the televisual experience, which is itself a fiction. Watching a Hollywood movie on TV may sometimes be an absorptive experience, in accordance with the ideal dynamics of "classical narrative cinema" described by psychoanalytic film theorists. ${ }^{14}$ The evening news may in some cases be less phenomenally engaging, regardless of whether an "interpellation" of subjectivity in dominant discourses and political interests somehow takes place between bites of a TV dinner. ${ }^{15}$ But genre, format, and content are not the sole determinants of our intentional engagement with television. Regardless of these factors, the viewer remains free to selectively engage and disengage, to get up and walk away, or to come back and "tune in." In any case, though, we do not typically believe as TV viewers that we could reach out and touch the things and people that constitute the objects of televisual mediation.

Apparently, though, televangelistic faith healing expects us to believe just that - i.e., that we can make physical contact with the faith healer despite the spatial (and temporal ${ }^{16}$ ) 
distance between us. To understand the televangelist's appeal to touch the screen, we must examine how it relates to the two models of phenomenal engagement with television that coexist in Wolff's analysis. First, the appeal must be seen as demanding that the viewer drop other concerns and concentrate intentional focus on the television, thus countering "normal" television-viewing in the mode of a non-exclusive distraction undertaken in parallel to "sewing, cooking, reading, eating." Significantly, when the televangelist asks us to touch the screen, he is asking us to literally and physically drop everything else: sewing needles, cooking utensils, books, knife and fork. One way of looking at this is to say that this corporeal disengagement with other activities aims to free subjective intentionality for an immersion in the televisually mediated "other world," which, according to Wolff, implies "a bracketing of the body." Accordingly, one phenomenological viewing modality makes way for the other and produces a radically intensified immersion, crowned by the belief that one could reach through the screen or enter the mediated world.

However, it would be wrong to assimilate the experience to the model of televisual immersion, intensified or not - and here we approach the specific internal modifications of worship and TV-viewing experiences that distinguish televangelistic faith healing from the external norms by which it is marginalized. For the ideal of immersion implies not only a forgetting of one's body and its immediate physical situation, but also a phenomenal disappearance of the concrete apparatus that frames and enables technically mediated experience - viz. the television set. (The paradigm, again, of such ideally "transparent" mediality is classical narrative cinema and its "suture" of the spectator into the diegetic world, where conventionalized continuity principles mask the medium's materiality and the apparatus escapes attention.) On this model, television instantiates what Don Ihde calls an "embodiment relation" with respect to the viewing subject; examples of such relations occur in standard usages of optical telescopes or microscopes, which allow human subjects to see through them to objects that are invisible (or indistinct) to the naked eye. ${ }^{17}$ The important point is that these mediators themselves withdraw from phenomenal awareness when appropriated or "incorporated" in purposeful directedness towards the objects of intentional focus. Subject and mediating technology act together as a symbiotic unit to reveal or intend a noetic object. ${ }^{18}$ But this model brings us back to conceiving the television, as it functions in televangelistic faith healing, as a prosthetic extension of the viewer's senses, as a transparent window onto a distant world. From here, it is but a short step to the misrecognition of televangelistic faith healing as attempting an impossible approximation of the unmediated, inperson experience of "live" faith healing.

But the call to touch the screen forces an awareness of the television set as an object in its own right. Corporeally "dropping" other activities, the viewer apprehends the apparatus first as a visual object and then, if he or she acts on the call to touch it, experiences it as a tactile presence, an inhumanly obdurate other. Indeed, this is an affront to, and a confrontation with, the notion of televisual immersion. The televangelist calls on the viewer to break the flow of distracted everydayness, where the TV functions as so much furniture or background noise, but he preempts as well the leap to engrossed absorption; forced to apprehend the television as a part of the physical setting of my living room, and feeling the screen's cool glass charged with an electro-static force field, I am reawakened to an awareness of my situated body. The body-screen juncture becomes a focal point of phenomenal engagement; however, it does not totally eclipse awareness of an additional object beyond the screen - the televangelist, who continues to speak to me, and whom I continue to intend as noetic terminus. Thus, there is a break here with the "embodiment relation" of televisual immersion, which can be symbolized as follows: 


\section{(viewer - television $) \rightarrow$ televangelist}

In opposition to this, there is something like what Ihde calls a "hermeneutic relation" instantiated here. In this type of relation, the technology is not transparent but opaque, and it is engaged as an object to be "read" or interpreted (hence engaged "hermeneutically"). The relation can be symbolized thus:

$$
\text { viewer } \rightarrow(\text { television }- \text { televangelist })^{19}
$$

Schematically, the TV set is placed on the right-hand side of the noetic arrow, indicating that it is not incorporated into subjectivity but relegated to the objective pole of the intentional relation. Nevertheless, it continues to mediate or "stand between" the viewing subject and the televangelist-as-interlocutor and -performer. The television, in this case, functions similarly to a radio telescope as opposed to an optical one: rather than looking through the apparatus, I must look at it in order to read off the information it gives me about the heavens beyond the ken of human vision. My ultimate interest is still "out there," beyond the apparatus, but to get there I must direct my focus closer to home - towards my interaction with the technical medium.

Before we rest content with this account, however, we should note that Ihde's phenomenological descriptions of human-technology relations are ultimately tuned to the rational epistemic goals of science. Though the models of embodiment and hermeneutic relations are illuminating for a wide range of extra-scientific interactions - notably for technologies' roles in secular contexts of media entertainment - their explanatory power is limited in cases of an ostensibly a-rational religious implementation. It is helpful in this regard to briefly re-examine the phenomenal relations involved in the less technically mediated context of in-church worship. I noted earlier the dual role of the pastor in Wolff's analysis: outside of church, he or she may be a friend, associate, or partner - a peer, an equal; but in the ecclesiastic setting, the pastor functions as a superior. Schematically, the everyday relation (friend $\leftrightarrow$ friend) gives way to the hierarchical relation (congregant $\rightarrow$ pastor). Moreover, the pastor qua pastor embodies a focal "site of interaction" between human and divine instances; he or she becomes a "medium" or "middle-man" between worshippers and God. As someone capable of relaying or "interpreting" God's will or word, the pastor is situated in something like a hermeneutic relation: [congregant $\rightarrow$ (pastor - God)]. Indeed, this hermeneutic relation might describe the role of the priest in Catholicism, but in the Protestant tradition - and especially in Christian fundamentalism and conservative evangelical traditions - God is accessible to the experience of the individual without the need for a middle-man. In Wolff's analysis of the Protestant service, the initial hierarchy gives way to an immersive inclusiveness as the individual congregant meshes into the collective body of the congregation, and the pastor, though still commanding respect, is integrated into this unity. An embodiment relation results: [(congregation - pastor) $\rightarrow$ God]; the parentheses here indicate the quasi-symbiotic assemblage of congregants and pastor, constituting a collective intentional unit. However, the collective "we" of (congregation - pastor) is here intending an object that is categorically immune to objectification; as the ground of all existence, God is neither subject nor object but inclusive of all subject/object relations and their constituent relata. Worshipful faith culminates in an openness to interconnection that effaces the remaining distance implied in the noetic relation of subjects intending an object; the arrow of intentionality points therefore not at God as a distant terminus but everywhere and nowhere. God is revealed in the tiniest speck of dust, in the greatest natural formations, in the 
monumental achievements of humanity, and in the concrete faces of other congregants. A new type of relation emerges, one that defies diagrammatic visualization, which we may label a "faith relation."

Though the faith healer operates with different means, the same sort of relation ideally applies. As an instrument of God or conduit for the Holy Spirit, the faith healer may be perceived in a hierarchical hermeneutic relation: [spectator $\rightarrow$ (faith healer - God)]. But the separation of the healer and the believer in need of healing must be overcome, and this is typically effected through physical contact, by means of a corporeal laying on of hands. Symbiotically and somatically, the two human actors intend God in a sort of embodiment relation [(spectator - faith healer) $\rightarrow$ God], but the transcendent, a-rational nature of God destabilizes the relation and - if the believer's faith is strong enough - gives way to a putatively immediate experience of the divine.

This analysis of the unstable and non-visualizable "faith relation" makes clear why churchgoers cannot expect televised worship services to affect them as deeply as congregational church services. For the last schematizable relation in faith's realization, the embodiment relation [(congregation - pastor) $\rightarrow$ God], involves the individual worshipper in a diffuse symbiotic subjectivity; subject to televisual mediation, this would render one of the following relations:

$$
(\text { viewer }- \text { television }) \rightarrow[\text { (congregation }- \text { pastor }) \rightarrow \text { God }]
$$

or

$$
\text { viewer } \rightarrow \text { television }-[\text { (congregation }- \text { pastor }) \rightarrow \text { God }]\}
$$

The first alternative, an embodiment relation à la televisual immersion, has the viewer "on the outside looking in," which can at best serve the testimonial purpose of demonstrating what it looks like for others to be engaged in worship - but without relaying that experience directly. The second, a hermeneutic relation, draws the viewer's attention towards the physical apparatus of mediation, the television, which could either be apprehended as a technological marvel or as an isolating barrier, but hardly as a conduit for participatory involvement. In either case, if television were really to transmit the same experience as in-church worship, the viewing subject would have to schizophrenically occupy two positions at once: that of the television viewer and the immersed congregant.

This is why religious programming in general, and faith-healing televangelism in particular-in so far as it aims to do more than just bear witness to others' experience of faith, discursively inspire viewers to seek redemption outside of television, or encourage believers and strengthen their resolve to live a Christian life, etc.- - must develop independent means of instantiating faith relations. And this is the significance of the televangelist's call to touch the screen; it effects a break with the embodiment relation of TV immersion by signaling a mutual awareness, on the part of the faith healer and viewer alike, of the mediating apparatus. This break is absolutely necessary, for though the televangelist may command the viewer's concentration, so long as intentionality is channeled in the mode of an embodiment relation the norms of face-to-face faith healing will apply; the broadcast may have a demonstrative value but will lack the performative dimension of instilling faith (or healing the viewer as a result). But the hermeneutic relation between viewer and television 
cannot be the final step, for the objectified screen hinders the direct contact necessary to "hands-on" faith healing and thus threatens to alienate the viewer.

Inducing awareness of the television as a concrete and recalcitrant object is thus only a preliminary step in the staging of a specifically technological test of faith. Though the ideal end result is structurally similar to the a-rational entwinement of inside/outside, subject/object, or particular/universal in the faith relations of non-televised church worship or faith-healing performances, here the technical means or conditions of televisual experience are of central significance. If faith healing is miraculous, televised faith healing is miraculous in a novel way. For the obdurate physicality of the apparatus must be overcome, in effect transubstantiated. Making contact with the faith healer despite the separation that is phenomenally concretized in the body-screen juncture becomes the equivalent of taking communion in church; the medium of television replaces the media of wafer and wine. But just as a subjective "suspension of disbelief" is inadequate to effect the miracle of bread and wine becoming flesh and blood, so too is an act of volition insufficient to overcome the technological obstacles to faith. Not a choice but a struggle, an ordeal is involved - not just of the individual against the machine, but of faith against technological modernity itself. Despite appearances to the contrary, this is a communal struggle, one that requires the joint effort of the believer and one who will show the way; however, it is not just the pastor who assumes the role of guide but the very apparatus of camera and screen that leads the viewer to the site of faith's realization. To grasp the ordeal, we must locate this site in context, i.e., come to terms with its place in the ritualistic and temporally unfolding processes of faith-healing broadcasts.

\section{The Place of Faith: Ritualistic Structures}

The church service thematized by Wolff again provides an instructive counterpoint. ${ }^{20}$ In a prelude to the service, music gently invites congregants to settle into their seats and bring conversations to an end; the ensuing silence promotes a meditative self-focus and a subjective separation from the everyday self and the secular organization of time. The superior value of ecclesiastic time is confirmed when the pastor steps up to the pulpit, to an elevated frontal position that simultaneously establishes an initial intersubjective hierarchy by visual means. A call for confession and forgiveness "frees up" congregants for the service proper, and an opening hymn commences the construction of a collective identity, whereby the "auditory unity" of song initiates a bracketing of the visual, tending towards immersion and away from hierarchical difference. The sensory mode of listening is prioritized in the sermons, prayers, and scripture readings that follow, and the pastor - who is both a member of the collective (one of us) and a privileged focal point of intentionality (someone who commands our attention, and not just any one of us) - oscillates between hermeneutic and embodiment relations. ${ }^{21}$ The special role of the pastor as mediator derives not from an authoritative superiority but from an instrumental facility in bringing the congregation into the right relation to God. Discursive segments are interspersed by collective singing, for which activity the congregants rise to their feet and the pastor often steps down, thus effecting a corporeal equalization of roles (active/passive, higher/lower) and promoting, through movement, an atmosphere of tactile connection in which the congregation increasingly "feels" God's presence. The taking of communion represents the climax of this progression, and it is here that the central miracle of the faith relation is performed. 
Comparing the ritual structures of faith-healing televangelism with those of in-church worship reveals both commonalities and significant technology-dependent differences. For example, Benny Hinn's half-hour program This is Your Day! is less insistent on the division between secular and religious time and space. ${ }^{22}$ An obvious reason, of course, is that the show is designed to be consumed in the privacy of viewers' homes, on a daily basis, and thus in between worldly activities - including the consumption of non-religious television. Indeed, the program both resembles secular television formats (such as the talk show) and explicitly distances itself from them (especially by thematizing differences of discursive content and value). A typical show starts out with a greeting and introduction from Pastor Hinn, who addresses the viewer directly with anecdotes, biblical references, and news from recent "Miracle Crusades." 23 Shortly thereafter Hinn introduces one or more guests with whom he discusses a given topic (often the subject of a guest's new book) over the following fifteen to twenty minutes. The shift from direct address to talk show-like discussion is made smoothly, but its occurrence is significant from a phenomenological point of view. The opening segment establishes Hinn's eloquence, friendliness, but also his authority; importantly, this is accomplished with the fixed gaze of a medium-shot camera that frames Hinn much like a TV news anchor. But the discussion segment flattens this hierarchy by means of dialogue, where Hinn is always appreciative of his guests' insights and wisdom; moreover, vision becomes dynamic, as the camera cuts from one interlocutor to another, panning or gently zooming in or out to reveal a luxurious but comfortable living-room setting. The viewer is integrated into this setting (which is not categorically different from the site of his or her own living room) largely as an unseen observer; only at key moments do the speakers turn and address the camera directly.

This integration, the means of which are structurally similar to classical narrative cinema and the embodiment relations of television in its immersive mode, thus functions similarly to the deployment of hymns in church; it works to break down the earlier established distance between viewer/congregant and pastor and to equalize their roles - but, crucially, it must do this without disengaging visuality. Indeed, visuality is central to the televangelist's medium, indispensable to tele-vision. The camera, an instrument of vision, must therefore take over the functions of collective song and the utilization in church rituals of congregants' motility and variable bodily comportment. Assuming an immobile, sofa-bound spectator, the camera can attempt to simulate corporeal movement by means of its own mobility: by tracking, cutting, panning, zooming. The continuity between the viewing setting (the viewer's living room) and the studio set (a simulated living room) supports the illusion of movement and the construction of embodiment relations between viewer and camera. However, as we have seen, this method may be suitable for involving the viewer in discursive exchanges or for testifying to acts of faith, but it cannot itself create or instantiate faith directly. Operating in this mode, the main segment of Hinn's show devotes much time to bearing witness: for example, in the form of anecdotes told by Hinn and his guests and of taped excerpts from live faith-healing crusades. Here the camera's mediation is not emphasized but bracketed as unimportant with regard to mediated content. But against this background, the punctuation of direct address, reserved after the introduction for key junctures, assumes an intensified significance by breaking the spell of unseen observation and placing the viewer in the position of the seen.

The idea is not that viewers are so naïve as to believe they are literally seen by the screen protagonists, but against the background of immersion, the direct address of the camera by Hinn or one of his guests abruptly calls viewers out and demands that they look at themselves. In the discursive context of the televised discussion, this technique is usually 
employed when a message has been expressed that calls for self-reflection on the part of the spectator - an examination of one's sinfulness or an assessment of one's faith. The deeper phenomenal significance lies in a reversal of noetic investment: the arrow of spectatorial intentionality, tending towards the camera's objects (the participants in the discussion and, by extension, the thematic contents of their discussion), is effectively hijacked and sent back to the viewer at its origin. The resulting relation of self-reflection does not, however, render the television superfluous, for it acts as the central enabling relay through which a subjective focus on self-as-object must pass. Furthermore, when discussants recognize the camera, they visibly break the immersive convention upon which the show has been operating, causing the viewer to recognize the screen and to reverse the habitual bracketing of mediation into which he or she has been gently lulled. Thus, this deployment of direct address stands in significant contrast to the show's opening segment, where direct address is used in a manner that is conventional for a wide variety of television formats and therefore hardly shocking. But the main segment's careful construction of embodiment relations, in which the television is phenomenally "absorbed" in the perception of its mediated objects, sets the stage for what now occurs as a sudden shift to a hermeneutic relation with the screen.

At one such juncture, the climactic high point of the show's progression has been reached. Having called viewers' awareness to their own subjective embodiment and to the television screen as the concrete, physical site of mediation, it is time for a prayer. It is in this context that the struggle of faith is to be enacted as the transubstantiation of the televisual medium, the otherwise isolating effects of which have been highlighted phenomenally by the shift to hermeneutic relations. Setting the mood, gentle music swells forth from the background - but it is hard to say whether it has just begun or imperceptibly been there all along. Now is the point in the order of service when Hinn occasionally suggests to viewers that they may wish to touch their televisions, effectively intensifying the perception of the medium as a barrier to tactile connection. The pastor closes his eyes to pray, inviting viewers to engage in the most paradoxical of viewing modes: watching $T V$ with your eyes closed. This form of engagement, singularly characteristic of televangelistic modes of address, announces that the definitive struggle of televangelistic faith healing is with the medium itself, with its central valorization of vision and with the distance and hierarchy involved in the visual perception of difference. With eyes closed and a hand on the screen, the serious "viewer" hears the pastor's charismatic prayer, interspersed with and followed by testimony that he "sees" someone being healed, raising hopes that it could happen to me too. But for it to occur, I must fight against what I, even as a believing viewer, know to be the case: that I am separated by great geographic distances from God's healing vessel, and that I am engaged in a non-normative or "abnormal" mode of viewing in a project or purpose that defies all scientific rationality. Hoping for nothing short of a miracle, I struggle with myself, with the conditions of technological mediation, and with the modern world for which the television stands in as proxy. The miracle of faith involves a non-rational leap across the gaps of a double mediation, by way of both the apparatus and the medium of the faith healer, to an inexplicable experience of God that sweeps up and synthesizes all separating differences. Centrally, the ambiguous God-experience, where the deity is both "out there" (hence separate and superior) and "in here" (indistinguishable and connected) is tuned to the paradoxical nature of televisual space and the medium's apparent (but normally only apparent) connections of inside and outside - of domestic space to distant locales and of embodied subjectivity to diegetic worlds.

Thus, external barriers to taking televangelistic faith-healing seriously have been recuperated as internal elements of its experience. That is, traditional church services are 
eschewed in the recognition that they cannot retain their effectiveness in the medium of television-where hymn-singing is likely to be experienced as anachronistically alienating rather than unifying in the absence of a congregation, and where the presence of other viewers is more likely to be inhibiting than inspiring. Additionally, external viewing norms are not rejected out of hand but appropriated and transformed from within: immersive embodiment relations are established to draw the viewer in, but they are then shattered to highlight the illusory nature of normative TV-mediated involvement. Here the awareness of separation that so detracts from the experience of religious television for Wolff's respondents is taken to an extreme and faced head-on (or, to be more precise, grappled with in a kind of "hands-on" struggle). Ideally, televangelistic faith healing produces a novel variety of religious experience that is unthinkable without technological mediation, inculcating an arational faith relation both by means of and against the normative structures of television viewership.

\section{Social Phenomena: Effects, Motivations, Situations}

Of course, not all viewers achieve this sublime contact, and even those who believe they do are not guaranteed health and prosperity. Importantly, these failures, which skeptics marshal against the plausibility of the enterprise, can also be taken up in a hermetically circular, unfalsifiable system and explained as the result of viewers' insufficient faith. Thus, viewers convinced of the basic system find here a reason not to turn away but to redouble their investments of energy - and of money. Significantly, the virtual collection plate occupies a prominent place in these shows; in the case of Benny Hinn, it is passed to the viewer (in the form of infomercial-like product-promotion) directly after "communion," when ecstatic feelings are highest, offering viewers either an opportunity to give thanks for success or, in case of failure, to "sow seed" for next time. ${ }^{24}$ It is this economic aspect of televangelistic faith healing that draws the sharpest criticisms for its instrumentalization of religious experience as a means of exploitation.

We come back to the social relations implicated in the format's phenomenal dynamics. The techno-phenomenological analysis undertaken here has intentionally bracketed these relations for the most part until now - not in order to downplay the social effects (including financial ruin or even refusal of medical care) or to deny the dishonorable intentions likely motivating many televangelists, but because I believe the subjective experience of devoted viewers has to be taken into account (and taken seriously) if one hopes to counter their exploitation by a system apparently impervious to rational criticism. On the other hand, however, my phenomenological description itself remains incomplete so long as it ignores viewers' social situations; phenomenal and social relations must be more explicitly correlated to do justice to the complex receptional dynamics of faith-healing televangelism. Specifically, we must place this extreme case back into the larger context of modern religious practices, consider the motivations for people's viewership, and explore the human significances and ideological capacities of mediating technologies in the conduct of worship.

First, it is important to note that faith-healing televangelism and traditional church services, as social phenomena, occupy positions on a continuum with regard to the roles of technology and mediation in worship. Even the least mediated of services, of course, will typically be facilitated by the use of electric lighting and conducted in a setting made hospitable for congregants by heaters or air-conditioners. Unless they malfunction, however, these technologies are hardly likely to occupy churchgoers' attentions; instead, they are 
invisible as part of the environmental background. ${ }^{25}$ Congregations or denominations that reject even these most basic of apparatuses (like some Old Order Amish groups) mark themselves as radically marginal to the modern world. Moving up a rung in the chain of technological mediation, it is altogether commonplace for churches of any significant size to employ PA-systems to ensure that the preacher's message reaches the ears of every congregant. More radically still, megachurches often use large-scale video screens, typically placed behind the preacher, in conjunction with sometimes multiple video cameras. It might seem to be but a small step from here to the mediation of televangelistic worship. However, sound systems and video displays are not meant to be perceived as objects in their own right but to be incorporated by congregants, in the mode of embodiment relations, as extensions of sight and hearing within larger architectural spaces. They function, therefore, quite differently from television in the extreme case we have been considering. Moreover, while megachurches do often televise their in-church services, these programs are best seen as further extensions of those services, channels by which to bear witness, spread the word to a larger audience, and advertise the congregation. They share a basic assumption common to a wide range of religious programming: that modern media can serve as a useful means in the fulfillment of an evangelistic mission. As we have seen, televangelistic faith-healing goes well beyond this instrumental view; television's normal functionality is broken at decisive moments so that it can no longer be conceived as a mere tool.

But even in the less radical mode of embodiment relations, the mediating technologies of modern worship never simply provide a neutral extension of natural perception or a nontransformative channel of communication. The megachurch's video screens literally channel vision, frame images in an altogether unnatural manner, and offer shifting perspectives unavailable to the bodily situated congregant. Video technologies therefore re-situate corporeally and socially situated congregants, re-position them with regard to intentional objects. But these perceptual transformations are not typically noticed or explicitly thematized, for video cameras and displays are employed according to conventions that derive from film, television, and even multimedia concert events - conventions of framing, continuity editing, and the like which permeate modern media as habitual, non-alienating structures of our historically conditioned seeing. As such, the technologies seem perfectly transparent in use, a fact which offers possibilities for putting them unobtrusively in the service of ideology. An oversized screen offers a unified vision shared by the entire congregation - hence a transcendence of congregants' unique spatial locations and perspectives that enables a new form of media-religious immersion in the space of the church. Cameras can thus steer collective perceptions by putting the preacher in a favorable light, and close-ups can underscore his or her words with a greater degree of expressiveness and emotional power. ${ }^{26}$ The message itself, under altered conditions of delivery and reception, cannot remain unaffected, nor can the general structure of the service avoid the impact of mediation. Indeed, the extreme case of televangelistic faith-healing demonstrates how "the same" goal (e.g., an experience of transcendence and interconnectedness in faith) is subject to radically different means of achievement as a result of media structures. Conversely, the failure of televised but otherwise traditional services to engage worshippers whose expectations are shaped by church gatherings suggests that some media are better suited than others for fulfilling particular functions or conveying certain messages. Seen in this light, it is therefore not surprising that religious TV has become as much a platform for politics as for worship; relying on media conventions established by secular broadcasting, religious talk shows naturally blend discussions of personal faith with broader social concerns, and specifically political messages are promoted in alternative news programs, 
where impressions of neutrality or objectivity are supported by mimicking journalistic modes of televisual communication.

These examples attest to a context-dependent ideological capacity of media that exceeds a neutral supplementation of discursive contents but instead transforms and, to a certain extent, even dictates the type and significance of messages relayed. The power of mediation, in these cases, derives from the lack of attention that it receives: the video screen seems merely to facilitate the pastor's communication in the megachurch, and the television screen recedes from view as it conforms to pervasive broadcasting conventions. Clearly, though, the fact that congregants and viewers see through these screens rather than looking at them is related to their historical and social situations in a media-saturated environment. Even if that environment is discursively problematized in sermons or televised discussions, such communications, as a condition of their effectiveness, depend upon and reinforce "normal" media relations - i.e., those that have been normalized in our socio-historical setting as the dominant, apparently neutral background of mediation. If we raise the question of ideological media-instrumentality in the extreme case of faith-healing televangelism, which also depends upon social norms of mediation and worship but as a backdrop against which to instantiate non-normative or deviant relations, we shall have to consider both the ends that such abnormality serves and the social circumstances under which it might seem attractive.

These are questions of motivation, and they may be asked in terms both of production and consumption. On the one hand, though, televangelists' intentions regarding the use of mediating technologies - whether sincerely believing more good can be done by reaching a mass audience or just desiring to generate larger profits - are hardly relevant from the perspective of a techno-phenomenological analysis. Such an analysis can neither help determine nor should it be influenced by these motivations, for the broadcasts' social and material effects are quite independent from any intended purpose. On the other hand, however, knowledge of viewers' motivations is of great relevance in assessing the significance of these effects for concretely situated subjects - and vice versa: by disclosing the ideal dynamics of the shows' medial structures, a techno-phenomenological investigation might in fact shed light on why, and under what conditions, people become "serious" participants in hand-on-the-screen televangelism.

Numerous studies have been conducted since the 1980s to determine who watches televangelistic programming and why. This empirically based research has revealed correlations between viewership and socioeconomic class, education, age, employment status, ethnicity, gender, and religious and political conservatism. Women, African Americans, the poor and unemployed tend to watch more often than middle-class white males; the elderly watch more than younger viewers; viewership is negatively related to education level; and it is positively related to affiliation or identification with both conservative evangelicalism and the political right. ${ }^{27}$ Often, explanations for statistical correlations have been sought in terms of sheer opportunity; thus, it is hypothesized that retired citizens, housewives, and the unemployed (among whom minorities and the lower classes are overrepresented) tend to watch more religious programming simply because they are at home more often, generally watch more television, and therefore comprise a readily available audience. ${ }^{28}$ Other approaches explore the links between audience profiles and the programs' contents; some researchers emphasize the predilection of conservative, evangelical, and "born again" viewers for programs that reinforce their independently held beliefs and values, suggesting that viewership cannot be determined simply by convenience. ${ }^{29}$ Others hypothesize a stronger link between viewership and social standing; televangelists' 


\section{Denson}

messages are seen to speak to experiences of disenfranchisement, marginalization, and resultant dissatisfactions with the perceived social order. ${ }^{30}$

Thus, empirical studies generally agree that televangelism attracts a heterogeneously marginalized audience base, but there is less agreement on whether this is merely coincidental or significant as a sign of viewers' reasons for tuning in. A technophenomenological analysis, because it describes medial experiences rather than providing causal explanations, cannot answer this question directly. However, it does highlight a blind spot in previous attempts to do so: framed in terms of programs' contents, discussions of viewers' motivations have tended to ignore the specifically medial character of televangelism, the largely unthematized material parameters of experience that underlie and condition the mediated communication and reception of discursive messages. In effect, then, these discussions take for granted the dominant model of television as a transparent channel or window; they thereby ignore the phenomenally unthematized transformative potential of media. By emphasizing the material experience of mediation relative to concretely embodied viewers, my analysis of faith-healing televangelism casts a new light on the controversies surrounding statistical correlations and suggests an alternative account of marginalization's significance. I propose, as a hypothesis in need of testing, that the structures of mediation employed in televangelism, and the relations enacted in viewing, provide a material link between viewers' social situations (marginal, assimilated, etc.) and their individually embodied experiences of them. As a point of "communication" between dominant social norms and those factors (such as gender, race, class, etc.) that mark individuals' approximation to or deviation from normative ideals, the medium itself is invested with an ideological function that may or may not be consonant with explicitly articulated contentlevel messages. ${ }^{31}$ Connecting public and private spheres, technological mediation thus plays a central (rather than supplementary) role in the negotiation of evangelicalism's liminal relations to secular modernity.

Specifically, the patterns of mediation employed in the extreme case of televangelistic faith healing encourage viewers to take up socially and materially abnormal relations to modern media (and, by extension, to modernity itself), to perform a self-marginalization that both mirrors and transforms the experiences of social marginalization to which, I propose, the form particularly speaks. Accordingly, on this view, it is the ritualistic reversals of normative media relations themselves that "speak" to viewers more powerfully and meaningfully than anything a televangelist might actually say in words. Against the background of normal viewing practices, which these programs initially encourage in the form of immersive embodiment relations, the rupture signaled by the call to touch the screen initiates an ordeal of faith that is simultaneously a personal religious struggle and an opportunity to confront by proxy the forces of isolation and separation that stand in the way of social integration. Encouraging an abnormal comportment towards the screen, the extreme form identifies the televisual medium's dominant promise of connection as illusory; it intensifies the experiential mismatch between televisually communicated social norms (facilitated through embodimentrelation immersion) and the bodily situation of deviance. Taking on objective opacity in an unconventional hermeneutic relation, the television thus gives material form to marginalized viewers' struggle to overcome separation and transforms their experience of marginality. Correlating the viewer's conflicted relations to discursive power structures in the public sphere, on the one hand, and a private struggle with the materiality of television as both a means and barrier to (phenomenal and social) integration on the other, faith-healing televangelism offers a potentially empowering experience of lived difference that allows the viewer to feel as if he or she is not merely a victim of society but actively involved in 
negotiating deviance as a positive attribute of existence. The point is not that viewers factually reclaim control over their own marginalized status, for clearly their experience is subject to ideological exploitation, thus rendering any felt empowerment illusory. Whatever the case may be, the experience itself remains powerful, and its power derives not from content-level enunciations designed to encourage or manipulate a disempowered audience but from the quasi-mimetic relations (in a Benjaminian sense) between public and private realms, between social discourses and the corporeal experience of technological mediation. What I have in mind here is the sense in which Walter Benjamin posits mimesis not as representational imitation but as a pre- or non-discursive corporeal practice capable of bypassing language and the level of "content," essentially opening a channel for direct impingement of technological media on affective embodiment. ${ }^{32}$ On this view, the resonance that extreme forms of televangelism find among (variously) marginalized audiences is not accidental; on the contrary, the pre-discursive "resonance" between normatively deviant social situations or identities and abnormal media relations provides a strong, material link and motivation for viewing. Televangelistic faith-healing provides an arena within which viewers may experientially transvalue marginalism and materially renegotiate their relations to secular modernity and its media.

On the other hand, the technological mediation of less extreme forms of televangelism and megachurch worship can be expected to resonate with the social situations of subjects whose involvement in the modern world is experienced as less problematic, with the experience of people who are less forcibly defined as deviant or who are unable or unwilling to marginalize themselves by taking up abnormal relations to media. The embodiment relations encouraged in more conventional religious programming or in megachurch settings allow discursive contents to occupy a more central role in recipients' intentional relations and thus grant a greater instrumental power to communicated messages. However, as we have seen, the structures of mediation employed may run counter to these messages, especially when they articulate criticisms of secular society and media, the conventions of which they crucially depend on. Thus, less radical media relations enable worshippers to distance themselves from mainstream society without effecting a radical break. Again, the structure of mediation can be seen to play a crucial role in determining which form will appeal to a particular social group.

Mediation is therefore not, I contend, a neutral supplement to content-level messages but constitutes an independent factor in the negotiation of an evangelical alternative public sphere - a heterogeneous social formation in which a variety of media uses fulfill various functions for differently situated subjects. It is thus imperative that we approach televangelistic programs (and mediated church worship) with an eye not only to the radical or moderate religious or political messages they express, but that we also differentiate them in terms of the types of material, phenomenal media relations they encourage. Only then can statistical correlations begin to provide meaningful information about mediated worship as a truly social phenomenon.

\section{Conclusion: Techno-Phenomenology and Empirical Testability}

I have sought in this paper to explicate the experiential relations involved in an extreme form of televised worship, and I have been led, on the basis of this techno-phenomenological description, to hypothesize more generally about the role of technological mediation in the negotiation of evangelicalism's liminal relations to secular modernity. I have aimed to illustrate the implications and explanatory scope of this hypothesis, but it remains tentative 


\section{Denson}

and in need of testing. Finally, doubts may linger about whether it can, in principle, be tested at all. I believe that it can, but doing so is no simple matter. Eliciting descriptions of worshippers' experiences in variously mediated religious contexts and, in the vein of Wolff's investigation, conducting phenomenological reductions of the results will be an indispensable starting point. But since, by hypothesis, the experiential resonances between social situations and medial structures are prior to and to some degree immune to discursive articulation or thematization, we should not expect viewers and congregants to explicitly corroborate my hypothesis. Thus, it will be necessary to conduct further techno-phenomenological investigations of a variety of worship situations and to carefully differentiate them according to their medial structures and the role technology plays in their experience. On this basis, more finely tuned correlations may be sought through empirical surveys that carefully distinguish among phenomenal modes of mediation, along with their relations to ritualistic structures, content-level messages, and the social backgrounds and situations of constituencies. Thus, though the hypothesized relations between mediality and social standing have slipped through the net of empirical surveys, a more finely meshed investigative matrix would in principle be capable of corroborating or disconfirming my central hypothesis. Even if this proposed research led to the rejection of my theory, I maintain that it is necessary to attend more carefully to the material and phenomenal relations implicated in technologically mediated worship, and I hope to have made here a preliminary step in this direction.

\section{Endnotes}

${ }^{1}$ This article has its origins in a collaborative effort between myself and Christoph Bestian, in which we sought to synthesize our areas of expertise in, respectively, phenomenological approaches to media and the sociology of religion in order to forge a type of media analysis that would be more robust than either of the individual approaches in isolation - a polyvocal approach able to draw strength from interdisciplinary dialogue and differences of perspective. Though I take responsibility for any shortcomings in this product of our collaboration, I am grateful to Christoph Bestian for making this article possible by challenging my views and placing them alongside a very different tradition of inquiry. I also thank Jatin Wagle for reading an early draft of this paper and providing detailed feedback on it.

${ }^{2}$ While it might be thought that this scenario is more of a stereotype than a reality, the appeal to touch the screen does in fact occur regularly in conservative American televangelism. As we shall see later, it occupies a central and highly ritualized position in televangelist Benny Hinn's long-running and popular program This is Your Day.

${ }^{3}$ A useful overview of the so-called "secularization debate" that ensued among sociologists of religion can be found in Swatos and Olson (2000).

${ }^{4}$ The precise determination of the term "evangelicalism" is controversial, as it covers a fairly wide range of theological positions (including conservative, fundamentalist, charismatic, Pentecostal, born-again, and certain ecumenical positions and movements), not all of which are comfortable with their being classed together. A common thread is an emphasis on evangelism, on actively spreading the word, from which practice evangelicalism takes its name. 
5 The idea of an "alternative public sphere" derives from Negt and Kluge (1993), who supplemented the theory of the bourgeois public sphere, as developed by Habermas (1991), with that of a proletarian public sphere. For an example of how the concept of an alternative public sphere has been applied to modern media culture, see Miriam Hansen (1991), where it is used to describe the social function of early cinema for women and ethnic groups in negotiating their places in early twentieth-century American culture.

6 The "techno-phenomenological" approach, which takes cues from Heidegger's (1962) famous tool analysis in Being and Time and from Merleau-Ponty's (2002) comments on cars, feather hats, and blind-men's canes in Phenomenology of Perception - and most directly from American philosopher of technology Don Ihde's phenomenological approach to mediating technologies $(1979,1991,2002)$ - is developed in Denson (2011). Further applications and explorations may be found in Denson (2007a, 2007b, 2009).

${ }^{7}$ Benny Hinn's syndicated television show, This is Your Day, has been on the air since 1990.

${ }^{8}$ See, in particular, Ihde (1991), as well as Ihde $(1979,2002)$.

${ }^{9}$ This is, of course, a central tenet of Marshall McLuhan's media theory, as summed in the programmatic slogan "the medium is the message" (see McLuhan, 1964); more recently, a form of this thesis can also be found in Friedrich Kittler's work (e.g. Kittler, 1999). It is my belief that much of the controversy over both of these theorists' alleged technological determinism could be avoided through careful phenomenological analysis, which bears out the non-neutrality of technology (and media technology) but not its deterministic interpretation.

${ }^{10}$ That is, while the extreme case is methodologically privileged in my investigation, this is not to be confused with a statement of its social or normative privileging, for straight-faced participatory engagement remains exceptional and, even in evangelical circles, regarded as non-standard or abnormal behavior.

${ }^{11}$ All page numbers indicated in parentheses in this section refer to Wolff (1999).

${ }^{12}$ I would like to emphasize that Wolff's article, "A Phenomenological Study of In-Church and Televised Worship," which I refer to throughout this section, is a rare example of a straightforward phenomenological engagement with televangelism and its experiential differences from churchgoing. Thus, though there are limitations, as mentioned above, with regard to the generalizations that can be made on the basis of Wolff's test group - limitations related to the specific cultural and historical setting of his investigation - Wolff's study is important less as an authoritative interpretation of a general ontological difference between televangelistic and in-church worship than as a particularly situated study that, in the following sections, will serve as an analytical counterpoint in my own attempt to come to terms with the experiential parameters of faith-healing televangelism.

${ }^{13}$ Wolff explains these dynamics with recourse to Joshua Meyrowitz's distinction between "private-public" and "public-public" events. According to Meyrowitz (1985, p. 287; qtd. in Wolff, 1999, p. 233): "Television takes already public events and makes them more than public. Perhaps we should distinguish between 'private-public' and 'public-public' events. By 'private-public,' I mean those events that involve public actions, but are still isolated in a 
particular time-space frame, and, therefore, are largely inaccessible to those not physically present. By 'public-public,' I mean those events that are carried beyond the time-space frame by electronic media, and therefore are accessible to almost everyone." Significantly, this opening of the "private-public" to the "public-public" (or the "more than public"), from which derives an embarrassing sense of inappropriateness (the sense of voyeurism that, in the case of televised church services, results from watching others engaged in deeply personal, sacred acts of worship), has been described by Baudrillard (1983) in terms of electronic media's usurpation of "the domestic scene of objects, with its rules of play and limits," by "a sort of obscenity where the most intimate processes of our life become the virtual feeding ground of the media" (p. 130).

${ }^{14}$ The now-classic exploration of the so-called "classical Hollywood style," to which these psychoanalytic theories pertain most centrally, is Bordwell, Staiger, and Thompson (1985). The absorptive potential of film has been described under the concept of "suture"; see Silverman (1986) for a classical statement.

15 The concept of "interpellation" derives from Louis Althusser (see Althusser, 1971) and played an important role in the psychoanalytic/Marxist film theory of the 1970s, especially in the so-called "apparatus theory" associated with Jean-Louis Baudry and the British journal Screen.

${ }^{16}$ Critics often note, for example, that Benny Hinn's shows are taped two weeks prior to broadcast - a fact that is seen to render the idea of tele-contact doubly improbable.

${ }^{17}$ A detailed exploration of phenomenal "embodiment relations" is to be found in Ihde (1991, pp. 72-80).

18 Other examples include Heidegger's (1962) famous hammer from Sein und Zeit and Merleau-Ponty's (2002) only slightly less famous example of the blind-man's cane from Phenomenology of Perception.

19 The concept of the "hermeneutic relation" is also explored at length in Ihde (1991, pp. 8097). My symbolization of these relations is also adapted from Ihde's own.

${ }^{20}$ Of course, it is important to keep in mind here that it is impossible to generalize from the church service described by Wolff, as the typical order of service may vary from denomination to denomination and from church to church. A denomination like the fundamentalist Church of Christ, for example, employs no musical instruments, so the "prelude" that Wolff describes is enacted in a different manner. Some churches distribute printed orders of service, and the sequence of events is therefore known beforehand, while other churches are more spontaneously organized. Despite minor and major differences, however, the ritual temporal progression described in the following provides important insights into the sensual dynamics of Protestant and evangelical church services that can be modified on a case by case basis.

${ }^{21}$ Thus, the pastor's special knowledge may be of central importance in the interpretation of scriptural passages, and he or she is thus individuated as a superior in a quasi-hermeneutic relation that is strengthened by the visual perception of distance and elevation. But in prayer, when vision's bracketing is literalized by the closing of eyes, the pastor as "spokesperson" is 
incorporated into the congregational body as its "mouthpiece," and all human participants are "equal in the sight of God."

${ }^{22}$ I concentrate on Hinn's program not because it is representative of televangelistic faith healing generally (for other shows employ radically different means), but because it presents a particularly subtle form of confrontation with and transformative appropriation of normative worship practices and viewing relations. Moreover, it is one of the most successful and longest running of currently broadcast religious programs to operate on the basis of faithhealing evangelism.

${ }^{23}$ While the itinerary that I describe here is indeed typical for Hinn's show, he also employs a variety of other formats, devoting episodes to extended footage of his stadium-filling crusades, to on-location excursions outside the studio, and to special "teachings" series, wherein Hinn explains his doctrines and justifies them on the basis of scripture. Nevertheless, the talk-show format discussed here dominates, and the other episode types tend to approximate its dynamics, especially in building up to a climactic prayer that, as I shall show shortly, implicates the viewer in a confrontation with televisual mediation.

${ }^{24}$ In Hinn's show, this constitutes the final segment of the program, and it occupies up to one-third of total air time (approximately ten minutes). In exchange for their "donations," viewers receive Hinn's books, DVDs, or paraphernalia such as a "names of the Lord bracelet."

25 Don Ihde discusses these so-called "background relations" in Technology and the Lifeworld (1991, pp. 108-112).

${ }^{26}$ It is worth noting that much of the performance is highly melodramatic, and melodrama in its many forms has a long history of utilizing technologies to achieve the illusion of a "direct" communication of basic emotions. Though it is beyond the scope of the present study to focus on these techniques, I refer the reader to two texts of fundamental relevance to this matter: Peter Brooks's The Melodramatic Imagination (1976), which traces the evolution of the melodramatic mode from the theatrical traditions of Revolutionary France, and Ben Singer's Melodrama and Modernity: Early Sensational Cinema and Its Contexts (2001), which focuses on early twentieth century American culture.

27 See, for example, the study by Stacey and Shupe (1982), which found televangelism's viewers tending to be older, female, working-class, less educated, and low-income; also, the Annenberg-Gallup poll, reported in Gerbner et al. (1986), which finds viewers tending to be female, older, conservative, and less educated; and the study conducted by Hougland, Billings, and Wood (1990), who find frequent viewing positively correlated with "low income, low education, and minority racial status," as well as "older age and nonmetropolitan residence (both of which may be associated with restricted employment opportunites)" (p. 59).

${ }^{28}$ Litman and Bain (1989) discuss this type of explanation in terms of an economic model of "opportunity cost of time and market income" (p. 333), but find only "partial support" for the theory (p. 340); Tamney and Johnson (1984) address this interpretation of statistical findings as the "opportunity argument" (p. 306), which they see refuted by their own findings. 
${ }^{29}$ Stacey and Shupe (1982) find a positive correlation between "electronic" and traditional religiosity (i.e., between televangelism viewing and traditional church attendance), but emphasize that this correlation is restricted only to certain denominational identifications: televangelism "preaches to the converted who are already predisposed, or self-elected, to seek out its messages. These are persons who are members of fundamentalist congregations and/or persons with highly orthodox religious beliefs" (p. 299, emphasis in original); see also Litman and Bain (1989), who find that "televangelist ministries are not evangelical in the sense of attracting a large audience to religion. Rather, they seem narrowly targeted to a highly selective audience which already has an affinity for their messages" (p. 339).

${ }^{30}$ See, for example, Bobby Alexander, Televangelism Reconsidered: Ritual and the Search for Human Community (1994), which posits that ritualistic participation in televangelistic programs "help[s] viewers legitimate or validate in their own eyes their religion, religious identity, and religious group in the face of threats and opposition by mainstream American society, which is highly secularized" (p. 4). Under the headings of the " privilegedeprivation' theory of religious participation" and the "surrogate family theory" (p. 332), where the latter is associated with the notion of "parasocial interaction" with television (p. 333), Litman and Bain (1989) test the hypothesis that televangelism speaks to "certain psychological states (e.g. feelings of deprivation and alienation)" (p. 340), but find only "partial support" on the basis of the "fairly strong association between age, unemployment and low education and the viewing of such television programs" (p. 340). Tamney and Johnson (1984), on the other hand, find no evidence for what they call the "powerlessness argument": "There is no reason to believe [...] that people watch religious programs because this allows them to lessen their sense of powerlessness through vicarious identification with televangelists" (p. 311).

${ }^{31}$ Certainly, the implications of this hypothesis are not limited to the realm of televangelism or the evangelical public sphere. If sound, my argument speaks to much more general mechanisms for the affective/embodied (i.e., pre- or sub-discursive) transfer or generation of political and ideological contents. I leave it as an open question in how far the hypothesis is congruent with Althusser's notion of "interpellation."

32 My thinking on this matter is indebted to Mark Hansen's Embodying Technesis: Technology Beyond Writing (2000), especially chapter 9: "On Some Motifs in Benjamin: (Re)Embodying Technology as Erlebnis, or the Postlinguistic Afterlife of Mimesis" (pp. 231263).

\section{References}

Alexander, B. C. (1994). Televangelism reconsidered: Ritual and the search for human community. Atlanta, GA: Scholars Press.

Althusser, L. (1971). Ideology and ideological state apparatuses (notes towards an investigation). In B. Brewster (Trans.), Lenin and philosophy and other essays (pp. 127-188). London: New Left Books.

Baudrillard, J. (1983). The ecstasy of communication. In H. Foster (Ed.), The anti-aesthetic: essays on postmodern culture (pp. 126-134). Seattle, WA: Bay Press 
Bordwell, D., Staiger, J., \& Thompson, K. (1985). The classical Hollywood cinema: Film style \& mode of production to 1960. New York, NY: Columbia University Press.

Brooks, P. (1976). The melodramatic imagination: Balzac, Henry James, melodrama, and the mode of excess. New Haven, CT: Yale University Press.

Denson, S. (2007a). Frankenstein, bioethics, and technological irreversibility. In B. Schreier (Ed.), Studies in irreversibility: Texts and contexts (pp. 134-166). Newcastle: Cambridge Scholars Publishing.

Denson, S. (2007b). Re-embodying the sonographic experience. Philament, 11, 64-67. $<$ http://www.arts.usyd.edu.au/publications/philament/issue11.htm>.

Denson, S. (2009). Between technology and art: Functions of film in transitional-era cinema. In D.M. Feige, T.Köppe, \& G. zur Nieden (Eds.), Funktionen von Kunst (pp. 127142). Frankfurt: Peter Lang.

Denson, S. (2011). Postnaturalism: Frankenstein, film, and the anthropotechnical interface. Unpublished dissertation, Leibniz University of Hannover.

Gerbner, G., Gross, L., Hoover, S., Morgan, M., Signorielli, N., Cotugno, H., \& Wuthnow, R. (1984). Religion and television. Philadelphia, PA: The Annenberg School of Communications.

Habermas, J. (1991). The structural transformation of the public sphere: An inquiry into a category of bourgeois society (T. Burger \& F. Lawrence, Trans.). Cambridge, MA: MIT.

Hansen, Mark (2000). Embodying technesis: Technology beyond writing. Ann Arbor, MI: University of Michigan Press.

Hansen, Miriam (1991). Babel and Babylon: Spectatorship in American silent film. Cambridge, MA: Harvard University Press.

Heidegger, M. (1962). Being and time (J. Macquarrie \& E. Robinson, Trans.). New York, NY: Harper \& Row.

Hougland, J. G., Jr., Billings, D. B., \& Wood, J. R. (1990). The instability of support for television evangelists: Public reactions during a period of embarrassment. Review of Religious Research, 32(1), 56-64.

Ihde, D. (1979). Technics and praxis. Boston, MA: D. Reidel.

Ihde, D. (1991). Technology and the lifeworld: From garden to earth. Bloomington, IL: Indiana University Press.

Ihde, D. (2002). Bodies in technology. Minneapolis, MN: University of Minnesota Press. 
Kittler, F. (1999). Gramophone, film, typewriter. (G. Winthrop-Young \& M. Wutz, Trans.). Stanford, CA: Stanford University Press.

Litman, B. R., \& Bain, E. (1989). The viewership of religious television programming: A multidisciplinary analysis of televangelism. Review of Religious Research, 30(4), 329343.

McLuhan, M. (1964). Understanding media: The extensions of man. New York, NY: Routledge.

Merleau-Ponty, M. (2002). Phenomenology of perception (C. Smith, Trans.). London: Routledge.

Meyrowitz, J. (1985). No sense of place: The impact of electronic media on social behavior. New York, NY: Oxford University Press.

Negt, O., \& Kluge, A. (1993). Public sphere and experience: Toward an analysis of the bourgeois and proletarian public sphere (P. Labanyi, J. O. Daniel, \& A. Oksiloff, Trans.). Minneapolis, MN: University of Minnesota Press.

Silverman, K. (1986). Suture. [Excerpts]. In P. Rosen (Ed.), Narrative, apparatus, ideology (pp. 219-235). New York, NY: Columbia University Press.

Singer, B. (2001). Melodrama and modernity: Early sensational cinema and its contexts. New York, NY: Columbia University Press.

Stacey, W., \& Shupe, A. (1982). Correlates of support for the electronic church. Journal for the Scientific Study of Religion, 21(4), 291-303.

Swatos, W. H., Jr., \& Olson, D. V. A. (Eds.). (2000). The secularization debate. Lanham, MD: Rowman \& Littlefield.

Tamney, J. B., \& Johnson, S. D. (1984). Religious television in Middletown. Review of Religious Research, 25(4), 303-313.

Wolff, R. F. (1999). A phenomenological study of in-church and televised worship. Journal for the Scientific Study of Religion, 38(2), 219-235. 